\title{
ASSOCIATION OF LOWER ANTIOXIDANT STATUS WITH ESTIMATED GFR IN HYPERTENSIVES WITH PRESERVED RENAL FUNCTION
}

Roma Rattan, Rasmita Kumari Padhy, Nirupama Devi, Suvendu Sekhar Acharya, Srikrushna Mahapatra

1. Assistant Professor, Department of Biochemistry, M.K.C.G Medical College, Berhampur.

2. Assistant Professor, Department of Biochemistry, M.K.C.G Medical College, Berhampur.

3. Associate Professor, Department of Biochemistry, M.K.C.G Medical College, Berhampur.

4. Assistant Professor, Department of Medicine, M.K.C.G Medical College, Berhampur.

5. Professor \& HOD, Department of Biochemistry, M.K.C.G Medical College, Berhampur.

\section{CORRESPONDING AUTHOR}

Dr. Rasmita Kumari Padhy,

Assistant Professor,

Dept of Biochemistry,

E-mail: padhyrasmita50@yahoo.in

Ph: 00919861093584

ABSTRACT: BACKGROUND AND OBJECTIVES: Renal dysfunction is end organ damage in hypertension. We investigated the association of oxidative stress with estimated glomerular filtration rate in hypertension._METHODS: A total of 116 hypertensive individuals (age $47 \pm$ 10.2 years; 68\% males; BMI < 25; without diabetes mellitus, CVD) were included. All the hypertensive subjects were albustix negative. Fasting blood glucose, lipid profile, urea and creatinine was estimated. Serum oxidant load was estimated by ferrous oxidation products in xylenol orange version 2(FOX2) and antioxidant power of serum was estimated by ferric reducing capacity, FRAP assay. Data is represented as mean \pm SD. Data was analysed by unpaired two-tailed students t test, Pearson's correlation and linear regression. The estimated GFR was calculated by simplified modification of diet in renal disease study prediction equation and Cockroft- Gault formula._RESULT: Systolic and diastolic blood pressure, lipid profile, serum creatinine and oxidant load was significantly higher in hypertensive subjects $(\mathrm{p}<0.001)$. Total Antioxidant status and estimated GFR was significantly lower in hypertensive subjects. A significant negative correlation was present between oxidative stress and eGFR. INTERPRETATION AND CONCLUSION: Among hypertensive subjects with preserved renal function increased oxidative stress is associated with decreased eGFR. Whether estimation of oxidative stress and adjuvant antioxidant therapy are better prognostic markers requires further research.

KEY WORDS: estimated GFR, hypertension, oxidative stress

INTRODUCTION: Hypertension (systolic blood pressure $\geq 140$ and diastolic blood pressure $\geq 90$ $\mathrm{mm}$ Hg mercury) is the most the most common cardiovascular disorder affecting every socio economic group of population (1). It is a major public health concern as it is associated with coronary artery disease, stroke, chronic renal disease and various other vascular complications (2). Recent studies have associated oxidative stress with the pathophysiology of hypertension induced renal dysfunction. Benign arterionephrosclerosis occurring in hypertensive patients leads to a mild to moderate increase in serum creatinine $(2,3)$. Normally the oxygen free radicals called as reactive oxygen species (ROS) are involved in maintaining cellular 
physiological equilibrium such as regulation of vascular tone, sensing of oxygen tension and signal transduction (4). Under normal physiological conditions the organism is protected from the toxic effects of ROS induced lipid peroxidation by antioxidants; however, when these antioxidants are overwhelmed, the organism is said to be under oxidative stress (4). Evidence suggests the association of oxidative stress in both experimental and human hypertension and renal dysfunction $(5,6)$. The role of oxidative stress in the pathogenesis of hypertension involves both hemodynamic (vasoconstriction) and structural (vascular remodeling) mechanisms (7-10). ROS may cause and maintain hypertension by various mechanisms such as quenching of vasodilator nitric oxide by superoxide, generation of vasoconstrictive lipid peroxidation products, damage to endothelial cells, damage to vascular smooth muscles, increase in intracellular free calcium, increased endothelial permeability, stimulation of inflammation and stimulation of growth signaling events (7-10). Studies suggest oxidative stress mediated inflammation and interstitial infiltration of immune cells cause renal cell injury and end organ damage of kidney in hypertension (11). The association between arterial hypertension and renal disease as a end organ damage is well established (12). In recent years it has been demonstrated that even minor renal dysfunction entail an enhanced cardiovascular risk and an increase in chronic renal failure due to hypertension $(13,14)$. The best measure of overall renal function is to measure the glomerular filtration rate (GFR). It is normally around $100 \mathrm{ml} / \mathrm{min}$ so that the result roughly indicates the percentage of normal renal function. Measurement of GFR is difficult but it can be estimated (eGFR) by laboratory from serum creatinine, gender, body surface area and age. Nevertheless, the available data are not conclusive and the relationship between oxidative stress, hypertension and renal dysfunction in humans remains to be elucidated. The purpose of the present study was to (a) investigate the association between hypertension, oxidative stress and estimated glomerular filtration rate (eGFR) in hypertensive subjects with preserved renal function and volunteer normotensive persons, (b) to find a correlation between serum oxidant load and serum total antioxidant status with eGFR.

MATERIAL AND METHODS: This case-control study included 116 hypertensive patients attending the Medicine outpatient department of MKCG Medical College, Berhampur. The study protocol was approved by the Institutional Ethical Committee. Informed consent was obtained from all the study participants. Study sample consisted of 232 individuals; 116 hypertensive subjects (cases) with the mean age of $47 \pm 10.2$ years, $68 \%$ male and having a body mass index (BMI) less than 25 and an equal number of age and sex matched controls.

The inclusion criteria for the cases were diagnosed essential hypertension with systolic blood pressure (SBP) $>140 \mathrm{~mm} \mathrm{Hg}$ and diastolic blood pressure (DBP) $>90 \mathrm{~mm} \mathrm{Hg}$ of either sex between the age group 30-65 years with a BMI $<25$ and without any associated diseases like diabetes mellitus, cardiovascular, liver or renal disease. Patients on medication like steroids, OC pills, thyroxin, HRT were excluded. Criteria for controls were age and sex matched healthy normotensive individuals without $\mathrm{H} / \mathrm{O}$ of hypertension.

The physiological parameters at the time of admission such as age, height, weight, duration of disease and blood pressure (BP) were recorded.

MEASUREMENT OF BLOOD PRESSURE (15): Each subject was seated in a quiet and comfortable position for five minutes, with feet on the floor and arm supported at heart level and then two readings of BP were measured on the right arm, five minutes apart with a mercury sphygmomanometer (cuff size 12.5 X $40 \mathrm{~cm}$ ) with auscultatory method of BP measurement. BP 
readings were confirmed in the contralateral arm at the same time. The SBP and DBP were read to the nearest $2 \mathrm{~mm} \mathrm{Hg}$. First and fifth phases of Korotkoff's sounds were taken as criteria for SBP and DBP respectively. The average of the two consecutive readings was recorded.

MEASUREMENT OF BIOCHEMICAL PARAMETERS: All the biochemical parameters were estimated in the clinical biochemistry laboratory at the Regional Diagnostic Centre of MKCG Medical College. Fasting venous sample was collected and the biochemical parameters were measured by using commercial kits adapted to EM360 Erba Transasia Autoanalyser. Glucose was estimated using glucose oxidase peroxidase method (Siemens), lipid profile parameters such as total cholesterol, triglycerides, HDL-Cholesterol was measured using kits from Erba diagnostics, Germany. LDL-Cholesterol was calculated using Freidewalds equation. Serum creatinine was measured using kits from Erba diagnostics, Germany. The estimated glomerular filtration rate was calculated by two different methods: simplified MDRD Study prediction equation (16) and Cockcroft-Gault (CG) formula (17). The CG formula was corrected for body surface area of $1.73 \mathrm{~m}^{2}$.

MEASUREMENT OF OXIDATIVE STRESS PARAMETERS: The oxidative stress was evaluated by estimating the amount of oxidant load of lipid peroxides was determined by ferrous oxidation products in xylenol orange assay in conjunction with triphenylphosphine version 2 (FOX2 assay) (18). The inter assay and intra assay coefficient of variation for FOX2 were $4.9 \%$ and $2.7 \%$ respectively. Antioxidant power of serum was measured by ferric reducing ability of serum (FRAP assay) (19). The inter assay and intra assay coefficient of variation for FRAP were $3.0 \%$ and $1.0 \%$, respectively.

STATISTICAL ANALYSIS: Data is expressed as mean \pm standard deviation (SD). The data was analyzed by student's t test for unpaired data. Correlation was derived by Pearson's correlation analysis. A p value $<0.05$ was considered significant. Statistical analysis was done using SPSS version 16 software.

RESULTS: Demographic profile of the study subjects is depicted in Table 1 and Figure 1. Cases included 79 males and 37 females with the male-to-female ratio of 2.13:1 and controls consisted of 65 male and 51 females with a male-to-female ratio of 1.27:1. Cases had a mean age of $47 \pm 10.2$ years compared to the mean age $44 \pm 7.8$ years of controls (table 1 ).

Clinical and laboratory data as represented in Table 2. SBP of cases $164.5 \pm 13.6 \mathrm{~mm} \mathrm{Hg}$ is significantly higher ( $\mathrm{p}$ value $<0.000$ ) and DBP $99.06 \pm 11.9 \mathrm{~mm} \mathrm{Hg}$ is significantly higher ( $\mathrm{p}$ value $<0.001$ ) than that of controls, with SBP $118.7 \pm 4.87 \mathrm{~mm} \mathrm{Hg}$ and DBP $82.34 \pm 3.5 \mathrm{~mm} \mathrm{Hg}$. There was no significant difference between the BMI of cases $(24.3 \pm 4.2)$ and that of controls $(24.06 \pm 3.7)$. Significant difference was not observed between the blood glucose of cases $(107 \pm 6.4 \mathrm{mg} / \mathrm{dl})$ and that of controls $(101 \pm 8.6)$. There was significant ( $\mathrm{p}$ value 0.001$)$ difference in the lipid profile between cases (total cholesterol-201.14 $\pm 6.12 \mathrm{mg} / \mathrm{dl}$; triglyceride- $159.18 \pm 11.7 \mathrm{mg} / \mathrm{dl}$; HDL cholesterol-36.07 $\pm 6.9 \mathrm{mg} / \mathrm{dl}$; LDLcholesterol-182.03 $\pm 14.86 \mathrm{mg} / \mathrm{dl}$ ) and controls (total cholesterol-147.41 $\pm 1.74 \mathrm{mg} / \mathrm{dl}$; triglyceride- $89.40 \pm 22.2 \mathrm{mg} / \mathrm{dl} ; \quad$ HDL cholesterol-31.08 \pm 3.59 $\mathrm{mg} / \mathrm{dl}$; LDLcholesterol-132.03 $\pm 18.07 \mathrm{mg} / \mathrm{dl}$ ). The serum creatinine level of cases $(1.18 \pm 0.04 \mathrm{mg} / \mathrm{dl})$ was significantly higher ( $\mathrm{p}$ value 0.001$)$ than controls $(0.99 \pm 0.1 \mathrm{mg} / \mathrm{dl})$. The eGFR of the cases $(58.70 \pm 24.19 \mathrm{ml} / \mathrm{min})$ was significantly lower in comparison to the controls $(94.18 \pm 10.31 \mathrm{ml} / \mathrm{min})$ as represented in Table 2 .

Table 3 and Figure 2 shows there is a significant increase in the oxidant load and a significant decrease in the total antioxidant power of the serum of hypertensive patients as 
compared to the normotensive controls. The serum oxidant load measured by FOX2 assay of cases is $13.0 \pm 4.9 \mu \mathrm{mol} / \mathrm{L}$ equivalent of hydrogen peroxide and that of controls is $4.33 \pm 1.7 \mu \mathrm{mol} / \mathrm{L}$ ( $\mathrm{p}$ value 0.001 ). The serum total antioxidant level of the cases is $99.87 \pm 7.48 \mu \mathrm{mol} / \mathrm{L}$ equivalent of Ferrous Sulphate and that of the controls is $423 \pm 15.23 \mu \mathrm{mol} / \mathrm{L}$. Pearson's correlation revealed a significant negative correlation between oxidant load and antioxidant status with $\mathrm{R}^{2}=-0.797$ and $\mathrm{p}$ value $=0.000$.

Table 4 and Figure 3 depict the correlation between the oxidative stress parameters and eGFR of the cases. Figure 4 shows the linear regression between oxidative stress parameters and eGFR in hypertensive cases. Linear regression shows that an increased antioxidant capacity of serum corresponds to increased eGFR and a high oxidant load predicts a decrease in eGFR.

DISCUSSION: Hypertension is a complex multifactorial disease of blood pressure regulation characterized by an increase in both systolic and diastolic blood pressure (SBP and DBP) than the optimal level. In the present study, the SBP and DBP of the cases were significantly higher than that of controls. Confounding factors which might influence the study parameters were minimized since all the participants were drawn from the same population. Almost all the study participants had similar diet and lifestyle with regard to their daily exercise patterns.

The findings of the present study demonstrate a strong association between blood pressure and oxidative stress parameters. The increased oxidative stress parameter levels observed in the hypertensive cases of our study is consistent with the findings of several previous studies (20-21). However, in certain studies no significant association was found between hypertension and oxidative stress, either due to the fact that these studies were conducted in the early stages of the disease or with patients receiving statins medication, which is an interfering factor of oxidative stress $(22,23$, and 24). The correlation of blood pressure with oxidative stress parameters in hypertensive subjects suggests that these parameters have a blood pressure modulating effect. Hypertensive cases showed an impaired total antioxidant status, which is in agreement with the previous studies (25-28). Further, the negative correlation between SBP and DBP with total antioxidant status assed by FRAP levels suggests the importance of serum antioxidant status in blood pressure modulation. In normotensives subjects there was no significant correlation between blood pressure and antioxidant status. This finding requires special analysis. Many recent studies have documented that exposure to ROS increase the expression of antioxidant enzymes such as superoxide dismutase, catalase, glutathione peroxidase $(29,30)$. Thus, genes encoding these enzymes are coordinately regulated by antioxidant responsive elements (ARE) in their regulatory regions, a process which occurs through the activation of transcription factor NF-E2-related factor 2 (Nrf2) (31). The binding of $\mathrm{Nrf} 2$ to ARE regions in genes causes up-regulation of the downstream genes which regulate the antioxidant activity of enzymes in response to ROS activity. It may be noted that this mechanism is triggered in most hypertensive patients in response to their increased oxidant load as compared to normotensives. The significant negative correlation between SBP vs FRAPS and DBP vs FRAP in hypertensive cases in our study strongly indicates the low antioxidant status of the patients leading to oxidative stress.

The low oxidative stress in hypertensives may be due to their decreased antioxidant defense activity and an increased oxidant load. This derangement leads to damage to various biomolecules in hypertensive patients. As a consequence, of increased oxidant load a reduction in endothelium- dependant vasodilation of vascular smooth muscles occurs in hypertensive patients $(32,33)$. This increase in blood pressure contributes to an increase in ROS and oxidant 
load, thereby enhancing the ROS- mediated hypertension through a complex interdependent cycle.

Previous studies have investigated and established significant association between oxidative stress and inflammation in hypertensive patients resulting in renal damage $(34,35)$. Our study, also demonstrated a significant correlation between increased oxidant load with eGFR in hypertensive patients. We also observed a significant positive correlation between decreased antioxidant status and eGFR. Based on these observations, it may be suggested that increased oxidative stress constitutes a powerful factor for promoting renal damage in hypertensive cases and it is in concordance with previous studies $(36,37)$. It has been observed that an increased oxidative stress in hypertensive cases activates various transcription factors such as NF-kB, activator protein-1, MAP kinases, p38 (36, 37, and 38). These transcription factors lead to rapid-response proinflammatory genes resulting increased interstitial inflammation, increased apoptosis and damage of renal tissue in hypertensives $(39,40)$. The significant negative correlation of oxidative stress with eGFR in hypertensive cases in our study indicates the association of oxidative stress with reduced renal functional status or the commencement of end organ damage.

The uniqueness of this study is that the hypertensive cases included although exhibited an increased serum creatinine level, had preserved renal function as implied by the negative albustix test done to detect urine albuminuria. However, our findings indicate the importance of oxidative stress parameters and eGFR in detecting early renal damage in hypertensive patients.

In conclusion, we suggest that antioxidant therapy may be included in adjunct with antihypertensive therapy to reduce oxidative stress induced end organ renal damage.

ACKNOWLEDGEMENT: Authors acknowledge the co-operation received from patients, volunteers and technicians and the help received from the scholars whose articles are cited and included in the references of this manuscript.

\section{REFERENCES :}

1. Park K. Hypertension. In Park's textbook of preventive and social medicine $20^{\text {th }}$ edition Park K. Jabalpur: M/S Banarasidas Bhanot 2009; 323-327.

2. Zuccala A, Fiorenza S, Rapana R and Santoro A. Hypertension, atherosclerosis and kidney. G Ital Nefrol 2005; 22 suppl 31: S9-14.

3. Rodriguez- Iturbe B, Vaziri ND, Herrara-Acosta J and Johnson RJ. Oxidative stress, renal infilteration of immune cells and salt- sensitive hypertension: all for one and one for all. Am J Physiol Renal Physiol 2004; 286: F606-F616.

4. Droge W. Free radicals in the physiological control of cell function. Physiol Rev. 2002; 82: 47-95.

5. Romero F, Herrara J, Nana M and Rodriguez- Iturbe B. Oxidative stress in renal transplantation with uneventful post operative course. Tranplant Proc 1999; 31: 23152316.

6. Wilcox CS. Reactive oxygen species: roles in blood pressure and kidney function. Curr Hypertens Rep 2002; 4: 160- 166

7. McIntyre M, Bohr DF, Dominiczak AF. Endothelial function in hypertension: the role of superoxide anion. Hypertension 1999; 34: 539-545 
8. Cracowski JL, Durand T, Bessard G. Isoprostanes as a biomarker of lipid peroxidation in humans: physiology, pharmacology and clinical implications. Trends Pharmacol Sci 2002; 23: 360-366

9. Vaziri ND, Ni Z, Oveisi F, Trnavsky- Hobbs DL. Effect of antioxidant therapy on blood pressure and NO syhtase expression in hypertensive rats. Hypertension 2000; 36: 957964

10. Zalba G, San Jose G, Moreno MU, Fortuno MA, Fortuno A, Beaumount FJ and Diez J. Oxidative stress in arterial hypertension: role of NADPH oxidase. Hypertension 2001; 38: 1395-1399

11. Martindale JL and Holbrook NJ. Cellular response to oxidative stress: signaling for sucide and survival. J Cell Physiol 2002; 192: 1-15

12. Perera GA. Hypertensive vascular disease: description and natural history. J Chronic Dis 1955;1: 33-42

13. Sarnak MJ, Levey AS, Schoolwerth AC, et al. Kidney disease as a risk factor for the development of cardiovascular disease: a statement from American heart association councils on kidney in cardiovascular disease, high blood pressure research, clinical cardiology and epidemiology and prevention. Hypertension. 2003;42: 1050-1065

14. Henry RM, Kostense PJ, Bos G et al. Mild renal insufficiency is associated with increased cardiovascular mortality: the Hoorn study. Kidney Int. 2002;62: 1402-1407

15. National high blood pressure education program. National institutes of health national heart, lung and blood institute. Complete report. The seventh report of the joint national committee on prevention, detection, evaluation and treatment of high blood pressure (online) 2004 Aug (cited 2009 Sep 23) URL:http: //www.nhlbi.nih.gov/guidelines/hypertension/jnc7full.pdf

16. Levey AS, Greene T, Kusek J, Beck G. A simplified equation to predict glomerular filteration rate from serum creatinine. J Am Soc Nephrol. 2000;11:155A

17. Cockcroft DW, Gault MH. Prediction of creatinine clearance from serum creatinine. Nephron 1976;16:31-41.

18. Benzie FFI, Strain JJ. The ferric reducing ability of plasma as a measure of antioxidant power: the FRAP assay. Analytical biochemistry 1996; 239: 70-76.

19. Halliwell B, Gutteridge JMC, eds. Free radicals in biology and medicine. 3rd ed. New York: Oxford University Press1999:298-299.

20. Simic DV, Mimic-Oka J, Pljesa-Ercegovac M et al. Byproducts of oxidative protein damage and antioxidant enzyme activities in plasma of patients with different degress of essential hypertention. J Hum Hypertens 2006;20: 149-155

21. Kedziora-Kornatowska K, Czuczejko J, Pawluk H, et al. The markers of oxidative stress and antioxidant activity of antioxidant system in the blood of elderly patients with essential arterial hypertension. Cell Mol Biol Lett 2004;9: 635-641.

22. Cracowski JL, Baguet JP, Ormezzano 0, et al. Lipid peroxidation is not increased in patients with untreated mild-to-moderate hypertension. Hypertension 2003; 41: 286288.

23. Ward NC, Hodgson JM, Puddey IB, Mori TA, Beilin LJ, Croft KD. Oxidative stress in human hypertension: association with antihypertensive treatment, gender, nutrition and lifestyle. Free Radic Biol Med 2004;36: 226-232.

24. Sugiyama M, Ohashi M, Takase H, Sato K, Ueda R, Dohi Y. Effects of atrovastatin on inflammation and oxidative stress. Heart Vessels 2005;20: 133-136 
25. Moreno MU, Jose GS, Fortuno A, Beloqui O, Diez J, Zalba G: The C242T CYBA polymorphism of NADPH oxidase is associated with essential hypertension. J Hypertens 2006;24: 1299-1306.

26. Kashyap MK, Yadav V, Sherawat BS, et al: Different antioxidants status, total antioxidant power and free radicals in essential hypertension. Mol Cell Biochem 2005; 277: 89-99.

27. Muda $\mathrm{P}$, Kampus $\mathrm{P}$, Zilmer $\mathrm{M}$, et al: Effect of antihypertensive treatment with candesartan or amlodipine on glutathione and its redox status, homocysteine and vitamin concentrations in patients with essential hypertension. J Hypertens 2005; 23: 105-112.

28. Russo C, Olivieri O, Girelli D, et al: Anti-oxidant status and lipid peroxidation in patients with essential hypertension. J Hypertens 1998; 16: 1267-1271.

29. Talalay P, Dinkova-Kostova AT, Holtzclaw WD: Importance of phase 2 gene regulation in protection against electrophile and reactive oxygen toxicity and carcinogenesis. Adv Enzyme Regul 2003; 43: 121-134.

30. Bae I, Fan S, Meng Q, et al: BRCA1 induces antioxidant gene expression and resistance to oxidative stress. Cancer Res 2004; 64: 7893-7909.

31. Lee JM, Johnson JA: An important role of Nrf2-ARE pathway in the cellular defense mechanism. J Biochem Mol Biol2004; 37: 139-143.

32. Lassègue B, Griendling K: Reactive oxygen species in hypertension. An update. Am J Hypertens 2004; 17: 852-860.

33. Touyz RM, Schiffrin EL: Reactive oxygen species in vascular biology: implications in hypertension. Histochem Cell Biol 2004; 122: 339-352.

34. Fliser D, Buchholz K, Haller H; European Trial on Olmesartan and Pravastatin in Inflammation and Atherosclerosis (EUTOPIA) Investigators. Antiinflammatory effects of angiotensin II subtype 1 receptor blockade in hypertensive patients with microinflammation. Circulation.2004;110:1103-1107.

35. Dohi Y, Ohashi M, Sugiyama M, Takase H, Sato K, Ueda R. Candesartan reduces oxidative stress and inflammation in patients with essential hypertension. Hypertens Res. 2003;26: 691- 697

36. Dro"ge W. Free radicals in the physiological control of cell function. Physiol Rev 2002;82: 47- 95.

37. Clerk A, Fuller SJ, Michael A, and Sugden PH. Stimulation of "stress-activated" mitogenactivated protein kinases/c-Jun N-terminal kinases, and p38 mitogen-activated protein kinases in perfuse rat hearts by oxidative and other stresses. J Biol Chem1998;273: 7228-7234.

38. Clerk A, Michael A, and Sugden PH. Stimulation of multiple mitogenactivated kinase subfamilies by oxaditave stress and phosphorilation of the small heat shock protein, HSP 25/27, in neonatal ventricular myocytes. J Biochem 1998; 333: 581-583.

39. Mervaala E, Finckenberg P, Lapatto R, Muller DN, Park JK, Dechend R, Ganten D, Vapaatalo $\mathrm{H}$, and Luft FC. Lipoic acid supplementation prevents angiotensin II-induced renal injury. Kidney Int 2003;64: 501-508.

40. Mu" ller DN, Dechend R, Mervaala EM, Park JK, Schimidt F, Fiebeler A, Theuer J, Breu V, Ganten D, Haller H, and Luft FC. NF_B inhibition ameliorates angiotensin II-induced inflammatory damage in rats. Hypertension 2000; 35: 193-201. 
Table 1 Age and gender distribution of the study group

\begin{tabular}{|l|l|l|}
\hline & Cases & controls \\
\hline Males & 79 & 65 \\
\hline Females & 37 & 51 \\
\hline M:F ratio & $2.13: 1$ & $1.27: 1$ \\
\hline Age & $47 \pm 10.2$ years & $44 \pm 7.8$ years \\
\hline
\end{tabular}

Table 2 Clinical and Laboratory Data of hypertensive cases and controls

\begin{tabular}{|l|l|l|l|}
\hline Parameters & Hypertensive cases & Normotensive controls & p value \\
\hline BMI $\left(\mathrm{Kg} / \mathrm{m}^{2}\right)$ & $24.3 \pm 4.2$ & $24.06 \pm 3.7$ & $\mathrm{NS}$ \\
\hline SBP $(\mathrm{mm} \mathrm{Hg})$ & $164.5 \pm 13.6$ & $118.7 \pm 4.87$ & 0.001 \\
\hline DBP $(\mathrm{mm} \mathrm{Hg})$ & $99.06 \pm 11.9$ & $82.34 \pm 3.5$ & 0.002 \\
\hline Blood glucose $(\mathrm{mg} / \mathrm{dl})$ & $107 \pm 6.4$ & $101 \pm 8.6$ & $\mathrm{NS}$ \\
\hline Total cholesterol $(\mathrm{mg} / \mathrm{dl})$ & $201.14 \pm 6.12$ & $147.41 \pm 1.74$ & 0.001 \\
\hline Triglyceride $(\mathrm{mg} / \mathrm{dl})$ & $159.18 \pm 11.72$ & $89.40 \pm 22.22$ & 0.000 \\
\hline HDL cholesterol $(\mathrm{mg} / \mathrm{dl})$ & $36.07 \pm 6.96$ & $31.08 \pm 3.59$ & $\mathrm{NS}$ \\
\hline LDL cholesterol $(\mathrm{mg} / \mathrm{dl})$ & $182.03 \pm 14.86$ & $132.03 \pm 18.07$ & 0.05 \\
\hline Serum creatinine $(\mathrm{mg} / \mathrm{dl})$ & $1.18 \pm 0.04$ & $0.99 \pm 0.11$ & 0.002 \\
\hline eGFR $(\mathrm{ml} / \mathrm{min})$ & $58.70 \pm 24.19$ & $94.18 \pm 10.31$ & 0.000 \\
\hline
\end{tabular}

Data is represented as mean \pm SD and analysed by unpaired student's $t$ test. Pvalue $<0.001$ and $<0.05$ are considered significant.

Table 3 Comparison of oxidative stress parameters between hypertensive cases and controls

\begin{tabular}{|l|l|l|}
\hline Parameter & Hypertensive cases & Normotensive controls \\
\hline FOX2 $(\mu \mathrm{mol} / \mathrm{L})$ & $13.0 \pm 4.9^{*}$ & $4.33 \pm 1.7$ \\
\hline FRAP $(\mu \mathrm{mol} / \mathrm{L})$ & $99.87 \pm 7.48^{*}$ & $423 \pm 15.23$ \\
\hline
\end{tabular}

Data is represented as mean $\pm S D$ and analyzed by unpaired student's $t$ test. *Significant with $p$ value $<0.001$ as compared to controls.

Table 4 Correlation between oxidative stress parameters with blood pressure and eGFR in hypertensive cases

\begin{tabular}{|c|c|c|}
\hline Parameters & $\begin{array}{c}\text { FRAP } \mu \mathrm{mol} / \mathrm{L} \\
\mathrm{R}^{2} \text { value; } \mathrm{p} \text { value }\end{array}$ & $\begin{array}{c}\text { FOX2 } \mu \mathrm{mol} / \mathrm{L} \\
\mathrm{R}^{2} \text { value; } p \text { value }\end{array}$ \\
\hline $\mathrm{eGFR} \mathrm{ml} / \mathrm{min}$ & $0.276 ; 0.02$ & $-0.53 ; 0.003$ \\
\hline SBP mm Hg & $-0.44 ;<0.005$ & $0.52 ;<0.005$ \\
\hline DBP mm Hg & $-0.49 ;<0.005$ & $0.55 ;<0.003$ \\
\hline
\end{tabular}


Figure 1 Gender distribution of the study group

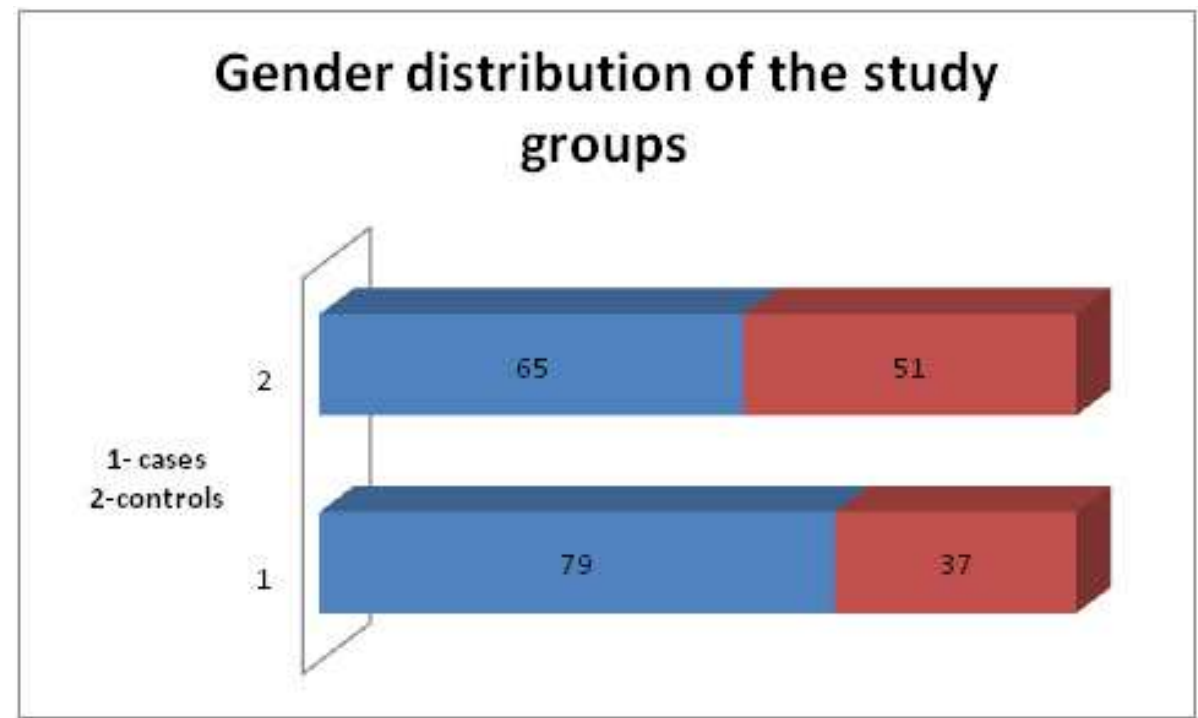

Figure 2 Relation of oxidant load and antioxidant status of the serum of hypertentive cases

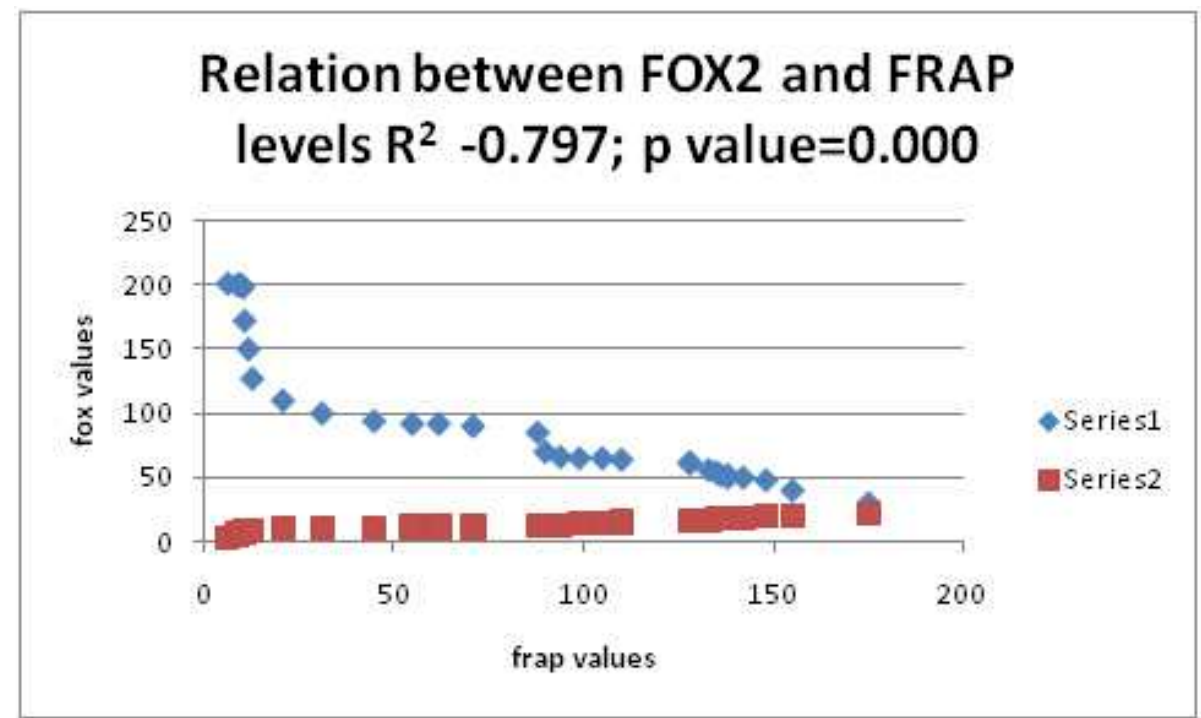

Series 1 depicts decreasing antioxidant (frap) levels and Series 2 shows increasing oxidant (fox $)_{2}$ levels. An increasing oxidant load corresponds to a decrease in antioxidant status leading to oxidative stress in hypertensive cases. 
Figure 3 Correlation of oxidative stress parameters- FOX2, FRAP with eGFR

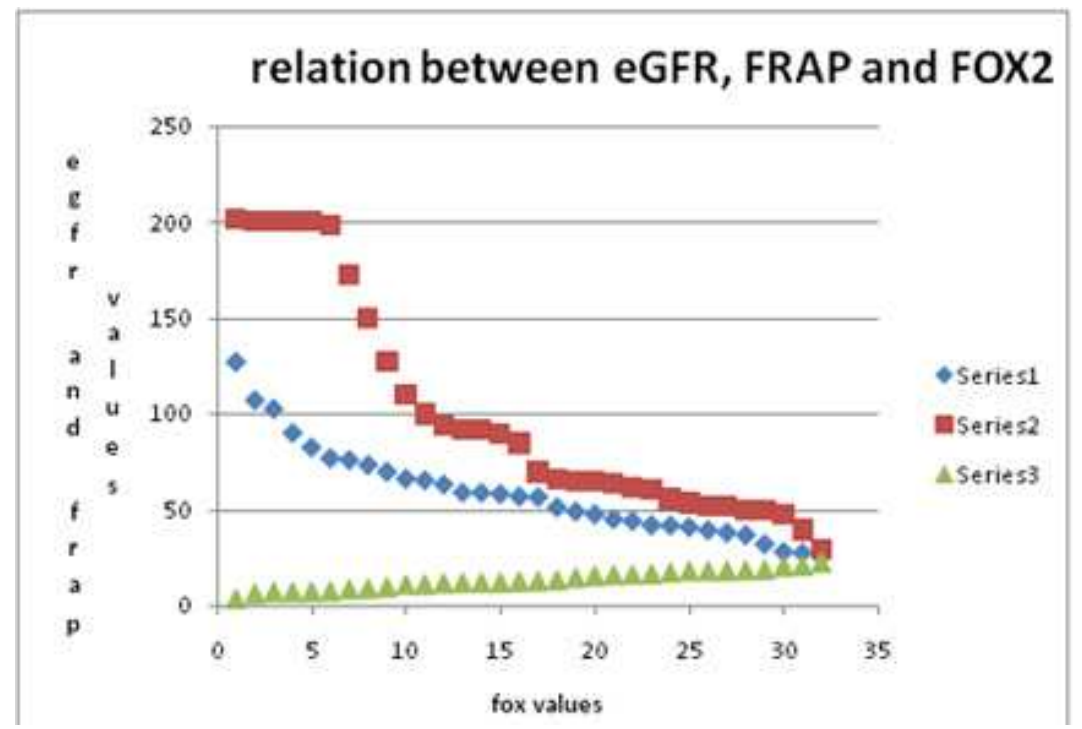

Series 1-eGFR, Series 2-FRAP, Series 3-FOX2. The graph shows negative correlation of FOX2 (increased oxidant load) with eGFR and positive correlation of eGFR with FRAP (antioxidant status) values.

Figure 4 A shows linear regression of eGFR with FRAP

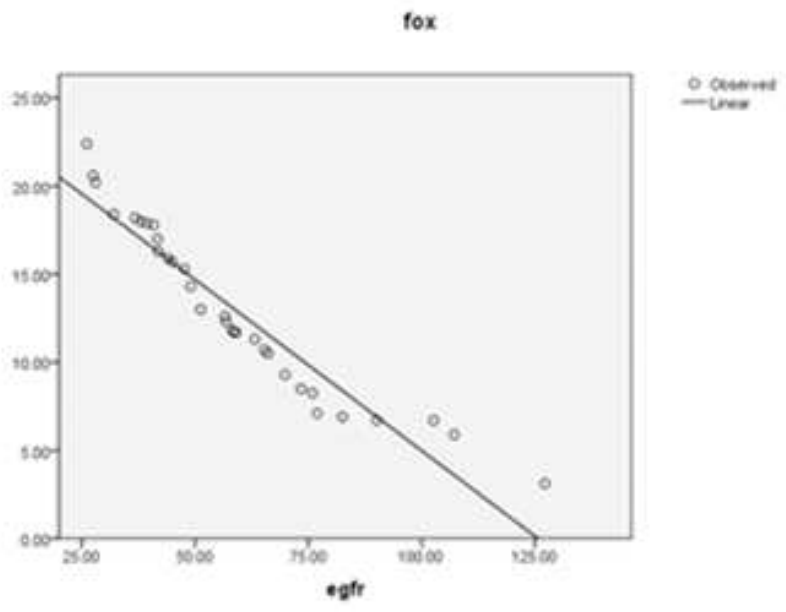


Figure 4 B shows linear regression of eGFR with FOX2

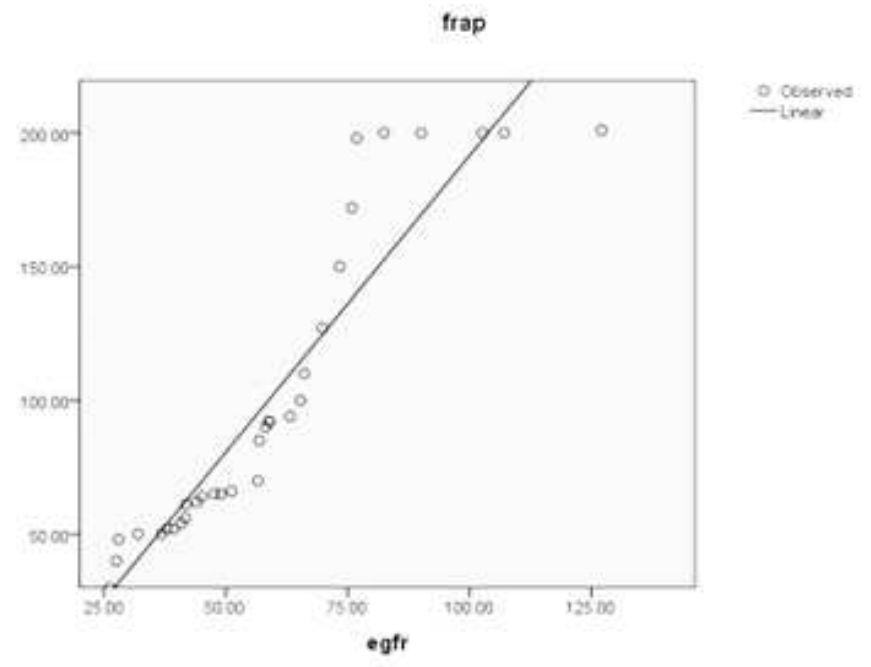

